\title{
Exploring the abundance-occupancy relationships for the Georges Bank finfish and shellfish community from 1963 to 2006
}

\author{
Michael G. Frisk ${ }^{1, *}$, Daniel E. Duplisea ${ }^{2}$, and Verena M. Trenkel ${ }^{3}$
}

\footnotetext{
${ }^{1}$ School of Marine and Atmospheric Sciences, Stony Brook University, Stony Brook, New York 11794-5000 USA

${ }^{2}$ Fisheries and Oceans Canada, Institut Maurice-Lamontagne, CP1000, Mont-Joli, Quebec G5H $3 Z 4$ Canada

${ }^{3}$ Institut Français de Recherche pour l'Exploitation de la Mer (IFREMER), rue de l'Ile d'Yeu, B.P. 21105, 44311, Nantes Cedex 03 France
}

*: Corresponding author : Michael G. Frisk, email address : $\underline{\text { mfrisk@notes.cc.sunysb.edu }}$

\begin{abstract}
:
Abundance-occupancy (A-O) patterns were explored temporally and spatially for the Georges Bank finfish and shellfish community to evaluate long-term trends in the assemblage structure and to identify anthropogenic and environmental drivers impacting the ecosystem. Analyses were conducted for 32 species representing the assemblage from 1963 to 2006 using data from the National Marine Fisheries Service's annual autumn bottom trawl survey. For individual species, occupancy was considered the proportion of stations with at least one individual present, and abundance was estimated as the mean annual number of fish captured per station. Intraspecific relationships were estimated to provide information on utilization of space by a species. Multispecies interspecific relationships over all species for each year were fitted to estimate assemblage structural changes over the time series. Results indicated that the slopes and strengths of interspecific A-O relationships significantly declined over the duration of the time series, and this decline was significantly related to groundfish landings. However, the rate of decline was not constant, and a breakpoint analysis of interspecific slopes indicated that 1973 was a period of "state" change. More importantly a jackknifeafter-bootstrap analysis indicated that the early 1970s followed by the 1990s were periods of higher than average probability of significant break points. While it is difficult to determine causation, the results suggest that long-term impacts such as habitat fragmentation may be influencing the species assemblage structure in the Georges Bank ecosystem. Further, we used slopes from the intraspecific A-O relationships to derive a measure of a species' potential risk of hyperstability, where catch rates remain high as the population declines. Combining this measure of the risk of hyperstability with resilience to exploitation provided a means to rank species risk of decline due to both demographics and the interaction of the behaviors of the species and fishing fleets.
\end{abstract}

Keywords : abundance-occupancy relationships, commercial catchability, community ecology, exploitation, finfish, fishing, Georges Bank, habitat fragmentation, hyperstability, resilience, shellfish 


\section{Introduction}

In recent decades it has become clear that ecosystem structure, process, and function undergo change, often over relatively short periods (Scheffer et al. 2001, Mangel and Levin 2005, Frisk et al. 2008). Regime shifts have been observed in a wide range of habitats including terrestrial, marine and freshwater environments (Carpenter et al. 2001, Ottersen et al. 2001, McGowan et al. 2005). Several mechanisms have been hypothesized as the cause for regime shifts including climate, nutrient loading, top-down control, fire suppression and harvest (fishing) (Fuller et al. 1998, Nystrom et al. 2000, Carpenter et al. 2001, van Langevelde et al. 2003, Collie et al. 2004, Cingolani et al. 2005, McGowan et al. 2005, Myers and Worm 2005). Moving beyond detecting regime shifts to prediction and management of highly altered ecosystems is a considerable challenge (Frisk et al. 2008); nevertheless, understanding large-scale ecosystem change is vital for informing management of the necessary steps to maintain desired ecosystem properties for multiple stakeholders.

One approach to understanding community structure is examination of the relationship between how a population utilizes its potential habitat (space) as a function of the abundance of the population. Abundance-Occupancy $(A-O)$ relationships describe how individuals maintain distance between each other in relation to the total number of individuals and can be seen as a reflection of intraspecific competition combined with social and reproductive behaviours. This approach can be applied to individual species or on a community level (Gaston et al. 2000). A$O$ relationships are useful in that they provide a metric for assessing the status of individual species, community structure, and resilience in response to natural or anthropogenic influences (Gaston et al. 2000).

Understanding A-O relationships is important because they reflect the susceptibility of a species to random environmental fluctuations and spatially confined mortality processes such as habitat fragmentation or fishing. A species with an $\mathrm{A}-\mathrm{O}$ relationship that strongly conserves local density would be highly susceptible to fisheries targeting aggregations (perhaps the last aggregation). This is one of the most compelling explanations for the notable decline of a once massive stock of northern Atlantic cod, Gadus morhua, which presently exists at about $1 \%$ of its peak biomass (Hutchings 1996). Furthermore, A-O relationships can suggest the spatial patterns of recovery under fisheries management strategies developed to promote population recovery. For example, the Icelandic migrating component of spring spawning Norwegian herring, Clupea harengus, was lost for more than 20 years, but subsequently recovered when the remaining coastal Norwegian population grew very dense locally (Anderson and Rose 2001, Huse et al. 2002, ICES 2007). Thus, recovery into areas where stocks are locally extinct may be driven by saturation in the A-O curve from the stock in adjacent areas, suggesting that there could be a means to predict probability of recovery throughout the historical stock area.

A-O relationships have been primarily fitted for single-species and populations over time where there has been enough contrast in the abundance within the time series to have some confidence in the fitted relationship. However, variation from the standard A-O relationship can also be fitted over multiple species within a system at a single point in time or over time. This resulting multispecies relationship may reflect community scale and spatial organizing (Holt et al. 2002). Interspecific A-O relationships may reflect competition between species as well as community response to external phenomena such as habitat fragmentation and loss (Donovan and Flather 2002, Freckleton et al. 2006). For example, an analysis of a time series of abundance and occupancy data for birds observed a weakening of the A-O relationship indicating a decoupling of community structure due to habitat fragmentation (Webb et al. 2007). 
Clearly, changes in interspecific A-O relationships are likely to reflect changes in either or both community structure and habitat.

Within a species range it is reasonable to assume that the highest density areas are regions of prime habitat and will likely be the area occupied at low population abundance (MacCall, A.D. 1990, Holt et al. 2002, Holt et al. 1997, Freckleton et al. 2006). A-O relationships show that the total amount of habitat, its patchiness and connectivity are related to population size, spatial distribution and rates of exchange between habitats. Clearly, removal (harvest) of species and habitat fragmentation is fundamental to the strength and, potentially, the shape of A-O relationships. The present study examines the A-O relationship for Georges Bank fish and invertebrate species caught in a groundfish survey conducted each autumn since 1963 . We examined both the intraspecific relationships for species and interspecific relationships for multispecies over time. Specifically, we analyzed: (1), the strength and shape of the A-O relationships for the duration of the times series; (2), the potential impacts of harvest on the strength and shape of A-O relationships; and (3), A-O relationships as an a priori method of determining the potential impacts of aggregation behaviour that may change catchability with changing population abundance.

\section{Methods}

\subsection{Data}

We analyzed data from the autumn National Marine Fisheries Service's (NMFS) bottom trawl survey (autumn: 1963-2006). The survey utilized a Yankee 36 bottom trawl equipped with a 1.27-cm mesh liner (Sosebee and Cadrin 2006). Stations consisted of tows 30 minutes in length at $1.95 \mathrm{~m} / \mathrm{s}$ (Sosebee and Cadrin 2006). The analyses herein only cover Georges Bank, representing 40-100 stations per year. The NMFS selects stations based on a depth-stratified random design (Sosebee and Cadrin 2006). Species included in the analyses were those that were captured 1000 times or greater and were captured in at least 40 years, which left us with a 32 species dataset.

\subsection{Abundance-Occupancy relationships}

Occupancy (O) for each species was estimated as the percent of all stations with at least one individual present. Abundance (A) was estimated as the average annual number of fish captured per station (catch per unit effort, CPUE). A log-linear model was used to describe the A-O relationship (Webb et al. 2007):

$$
O=s \cdot \log (A)+C
$$

where $s$ and $C$ are the fitted slope and intercept, respectively. While the model provides information on the ecological structure of species and the community, model parameters do not represent specific mechanisms underlying observed relationships; instead they are used to compare relationships between species and trends in assemblage structure. For fitting A-O relationships, we used an abundance minimum of 0.01 individuals / haul and removed species if they did not meet this criterion. 


\subsection{Fitting and Statistical Analysis}

Models were fitted in the statistical software R using standard least squares with the "Im" function both for single species over years (intraspecific) and also over species within a year (interspecific). Parameters of fitted models were compared for the interspecific time series and residual values were examined for evidence of changing quality of fit. Quality of model fit was assessed with $r$-square $\left(r^{2}\right)$ values.

Segmented regression with a breakpoint analysis was performed on the time series of fitted parameter values and $r^{2}$ values for interspecific A-O relationships to identify years where important changes in A-O occurred. This analysis was performed using the "strucchange" package in $\mathrm{R}$. This method fits a series of linear regressions between breakpoints and parsimoniously optimizes the increase in quality of the overall fit of the segmented regression while penalizing the number of breakpoints in the series using the pseudo-Bayesian statistic Bayesian Information Criterion (BIC).

\subsection{Bootstrap of breakpoint analysis}

In order to determine the influence of individual species on the breakpoint year for the slope of the fitted A-O relationship we performed two kinds of analysis: a simple jackknife where the breakpoint was determined for a dataset successively excluding one of the 32 species and a more detailed jackknife-after-bootstrap (JAB) analysis. Neither of these analyses involved the testing of a null model, but helped us understand the influence of each species on the overall result. For the JAB analysis, 40,000 A-O datasets of 32 species were constructed by sampling the species vector with replacement; therefore, there was no shuffling of $O$ or $A$ between species or between years. The interspecific A-O model was then fitted to each of the 40,000 datasets and the breakpoint analysis applied to the slopes of the fitted model. From this suite of results, each species was then selected in series to determine the frequency of each breakpoint year when that species was included in one resampled dataset. We also determined the percentage of resampled datasets which included a particular species where at least one significant breakpoint of the trend in slopes was found.

The JAB analysis was performed in addition to simple jackknife analysis because it captures some of the potential synergistic effects between species. That is, it may be meaningless to remove one species without removing one or more others as strong co-dependence may occur between certain species. The JAB analysis also separates species in some resampled datasets but in others it maintains species together. We assume that through the large number of resampled datasets $(40,000)$ the net influence of this effect is nullified which is not the case with the simple jackknife analysis.

\subsection{Temporal trends in abundance and percent occupancy}

Spearman's rank correlation between species abundance and time and the correlation of percent occupancy and time were estimated (Fisher and Frank 2004). To investigate the impact of species aggregate abundance trends on the intercepts $(C)$, slopes $(s)$ and strengths of the interspecific A-O relationships, the abundances of flatfish, gadoids, pelagics, others, and small elasmobranchs were regressed against the intercepts, slopes, and strengths of A-O relationships (see Table 3 for species grouping). If significant trends were estimated, the 
Durbin-Watson statistic was used to determine if $1^{\text {st }}$ order autocorrelation affected model estimates.

\subsection{Harvest and A-O relationships}

The effects of annual harvest on the community (interspecific) A-O structures were explored by regression analysis. Landings data were obtained from NOAA: Office of Science and Technology for the bottom otter trawl fisheries in the New England region for years 1963-2004. The Durbin-Watson statistic was estimated to determine if $1^{\text {st }}$ order autocorrelation exists in the relationships.

\subsection{Derivation of delta $q$ catchability $(\Delta q)$}

Catchability is defined as the proportion of the stock sampled for one unit of effort. The relationship between occupancy, abundance, and commercial catchability has been studied by several authors (Swain and Sinclair 1994, Ellis and Wang 2007). The two elements to this relationship are the type of spatial distribution of the resource and the fishing effort allocation distribution model. Occupancy is measured in this manuscript by the proportion of positive hauls. For a constant sampling design (constant haul duration and number of hauls) this is equivalent to the proportion of sampled area with density above some fixed value. This measure of occupancy is sensitive to both changes in overall abundance, i.e. densitydependence and changes in spatial spread, i.e. density-independence (Swain and Sinclair 1994). Several effort allocation models can be formulated. In the simplest (unrealistic) case, effort allocation is distributed randomly, which is actually what the survey does. More realistic models assume that fishing effort is allocated proportionally to local density or concentrated in high density areas. In the last two cases of spatially targeted fishing effort, populations with higher spread for the same total abundance have lower catchabilities (see Fig 4 in Swain and Sinclair 1994) for a given effort level. For a spatial distribution described by a Gaussian distribution and an effort distribution that follows it, catchability is inversely related to the standard deviation of the spatial fish distribution (see Fig 4 in Swain and Sinclair (1994) and also the appendix of Ellis and Wang (2007)). Thus, high values of the slope (s) in the A-O relationship (eq 1) indicate higher spatial spreading, which is equivalent to a spatial distribution with a large standard deviation, and thus lower catchability compared to smaller slope values. We therefore take the inverse of the slope value as an indication of differences in catchability. Thus, for a given abundance, a species with lower slope values have a tendency to aggregate and have greater catchability. This measure provides an indication of the potential of hyperstability where catch rates will remain high as the population declines and is termed delta $q(\Delta q)$.

\subsection{A-O relationships, catchability and population resilience}

Delta $q(\Delta q)$ was estimated for all species in the time series providing an indication of the potential for hyper-stability where catch rates will remain high as the population declines. In an effort to assess the impact of changes in catchability, abundance, and population resilience, a ranking system was developed combining $\Delta q$ and a measure of population resilience. Resilience estimates were based on biological parameters (growth rate, age at maturity and lifespan) and provided a measure of productivity in the following categories: high (von Bertalanffy growth coefficient $(k)>0.3 \mathrm{yr}^{-1}$, age at maturity $\left(t_{\operatorname{mat}}\right)<1 \mathrm{yr}$, longevity $\left.\left(\mathrm{t}_{\max }\right)=1-3 \mathrm{yr}\right)$, 
medium $\left(\mathrm{k}=0.16-0.30, \mathrm{t}_{\mathrm{mat}}=2-4, \mathrm{t}_{\max }=4-10\right)$, low $\left(\mathrm{k}=0.05-0.15, \mathrm{t}_{\mathrm{mat}}=5-10, \mathrm{t}_{\max }=11-30\right)$, and very low $\left(k<0.05, t_{m a t}=>10, t_{\max }>30\right)$ (Musick 1999). Values were taken from FishBase.org and provide a general picture of a population's turnover rate. Further, we developed a risk measure designed to identify species with low resilience and potential for hyper-stability. The logic here is that species with lower s (slope) values are at risk of targeted fisheries operating at high catch rates, while the population rapidly declines, and with low resilience would take a long time to recover from depletion.

\section{Results}

\subsection{Intraspecific Abundance-Occupancy relationships}

The log A-O model fits for each species had slopes significantly different from 0 at the five percent level. The individual slopes ranged from 0.016 (pollock) to 0.177 (American lobster) and averaged 0.07 (Table 1). Only one species (Longhorn sculpin) had an $r^{2}$ value less than 0.2 while the average $r^{2}$ was 0.48 . A single model fitted to all species and years shows that the community of species follows a general pattern similar to that observed for individual species (Figure 1, thick line).

\subsection{Interspecific A-O relationships}

Interspecific analysis showed that over time the slopes (s) of A-O relationships decreased (became less steep) indicating an increasing propensity over time for individuals of all species to be found in fewer localities for the same level of abundance (Figure 2a, Table 2). Simultaneously, the quality of the fit of the A-O relationship decreased $\left(r^{2}\right.$ decreased) (Figure $2 b)$. Breakpoint and segmented regression analysis revealed a single break in the slope (s) in 1973 such that from 1963-1973, the slope steeply declined (i.e. all species were occupying fewer locations over time) while after 1973 the slope still declined but at a slower rate (Figure 2a). No significant breakpoints were found for $r^{2}$.

The simple jackknife analysis showed very little influence of species on the 1973 breakpoint of the slope of the complete dataset. The exceptions occurred when butterfish were excluded and no significant breakpoints were found and also when silver hake were excluded which led to 1979 in addition to 1973 as a significant breakpoint in slope. The JAB analysis (Figure 3) showed that the inclusion of red hake and northern shortfin squid in datasets tended to move the median breakpoint to 1975 , notably because these two species also forced a larger than normal percentage of breakpoints in the 1980s and 90s. Inclusion of northern shortfin squid in resampled datasets tended to reduce the probability of finding breakpoints at all (only 29\%), while for red hake the percentage of datasets having a breakpoint was 59\%. This compares to a median probability of finding a breakpoint of about $53 \%$. The inclusion of butterfish in a community dataset reduced the probability of finding a secondary breakpoint in years after 1973 but gave a relatively high probability of finding a breakpoint in 1973 or earlier. Overall, there was little influence from individual species on the breakpoint year that would affect the evaluation of a breakpoint occurring with perhaps the exception of northern shortfin squid. 


\subsection{Temporal trends in abundance and percent occupancy}

Significant correlations between abundance and time were estimated for 20 of the 32 species with 17 showing positive trends and 3 with negative trends (Figure 4, Table 3). Significant correlations between percent occupancy and time were estimated for 16 of 32 species with 9 positive and 7 negative. Notable correlations $(> \pm 0.50)$ in abundance and time included thorny skate (-0.68), fourspot flounder (0.75), sea scallop (0.65), Atlantic herring (0.64) and silver hake (0.54). In 7 cases significant relationships between abundance and time displayed autocorrelation. Several species had strong correlations between percent occupancy and time including thorny skate (-0.84), Atlantic cod (-0.69), white hake (-0.54), sea scallop (+0.70), and fourspot flounder $(+0.60)$. In four cases significant relationships between occupancy and time displayed autocorrelation.

The intercepts $(C)$ of the interspecific A-O relationships were significantly $(-)$ related to the aggregate abundances of species in the others group $\left(n=44, r^{2}=0.16, F=8.16, p=0.007\right)$ and small elasmobranchs $\left(n=44, r^{2}=0.11, F=5.19, p=0.028\right)$. Abundances of flatfish, gadoids and pelagics were not significantly related to the intercepts of the A-O relationship $(p=$ $0.661,0.285,0.089$, respectively). The slopes $(s)$ of the interspecific A-O relationships were significantly $(-)$ related to the abundances of pelagics $\left(n=44, r^{2}=0.13, F=6.03, p=0.018\right)$ and others $\left(n=44, r^{2}=0.11, F=5.40, p=0.025\right.$ ), but was not significantly related for small elasmobranchs, flatfish, and gadoids ( $p=0.102,0.649,0.103$, respectively). Percent occupancy of gadoids was significantly $(+)$ related to the intercepts of the A-O relationship $(n=$ $\left.44, r^{2}=0.25, F=14.16, p=0.000\right)$. Percent occupancy of flatfish, small elasmobranchs, others and pelagics was not significantly related to the intercepts of the A-O relationship $(p=0.16$, $0.357,0.107,0.382$, respectively). The slopes (s) of the interspecific A-O relationships were significantly $(+)$ related to the percent occupancy of flatfish $\left(n=44, r^{2}=0.10, F=4.55, p=\right.$ $0.038)$ others $\left(n=44, r^{2}=0.11, F=5.11, p=0.029\right)$ and gadoids $\left(n=44, r^{2}=0.23, F=12.94, p\right.$ $=0.000)$, but were not significantly related for small elasmobranchs and pelagics $(p=0.412$ and 0.545 , respectively).

\subsection{Harvest and $\mathrm{A}-\mathrm{O}$ relationships}

Landings were positively associated to the slopes $(s)$ of the interspecific A-O relationships $(s=$ $0.0000001 \bullet$ landings $+0.063, r^{2}=0.37, p<0.001$; Figure 5). Autocorrelation with time was not found (Durban-Watson $=1.78, p_{>D W}=0.81, p_{<D W}=0.18$ ). The strength of the interspecific $A-O$ relationships was also positively associated with landings $\left(r^{2}=0.000001 \bullet\right.$ landings $+0.42, r^{2}=$ $0.24, \mathrm{p}<0.001$ ). Autocorrelation with time was not significant (Durban-Watson $=2.14, \mathrm{p}_{>\mathrm{DW}}=$ $\left.0.38, \mathrm{p}_{<\mathrm{DW}}=0.62\right)$.

\subsection{A-O relationships, catchability and population resilience}

Delta q $(\Delta q)$ ranged from 5.65 (American lobster) to 62.22 (pollock) with an average of 19.43 (Table 1). The species with the highest eight $\Delta q$ values were pollock, blackbelly rosefish, Acadian redfish, fawn cusk-eel, Gulf Stream flounder, Atlantic mackerel, witch flounder, and Atlantic herring. Of these, one was categorized as having very low resilience (blackbelly rosefish), two with low (Acadian redfish and witch flounder), three with medium (pollock, Atlantic mackerel, Atlantic herring) and two with high (fawn cusk-eel, Gulf Stream flounder). 
Species population resilience measured as productivity defined by biological parameters of growth, maturation and fecundity was plotted against $\Delta q$ (Figure 6). Species were grouped by resilience and $\Delta q$ to provide a relative measure of risk of hyper-stability leading to continued high catch rates, for targeted fisheries, where the population is declining and has low potential population recovery. Species with high $\Delta q$ values and low resilience were considered at greatest risk and species with low $\Delta q$ values and high resilience as lower risk. In addition $\Delta q$ and resilience values were standardized and summed to create a ranking of species at risk of high $\Delta q$ and low resilience values (Figure 7 ).

\section{Discussion}

The existence of positive intra- and interspecific A-O relationships is confirmed by many empirical and experimental studies and is considered to be a corner-stone of macroecology for both terrestrial and marine systems (Blackburn et al. 2006, Gaston et al. 2000). A range of explanatory hypotheses have been put forward for both intra- and interspecific relationships, with the most likely explanations deriving from resource availability, habitat selection and local population dynamics, including dispersal and metapopulation effects (Gaston et al. 2000). Here we presented the intra- and interspecific abundance-occupancy (A-O) relationships for the Georges Bank finfish and shellfish community from 1963-2006. Breakpoint analyses suggested that the slopes and strengths of the interspecific A-O relationships significantly declined over the duration of the times series and were positively related to groundfish landings. Jackknife-afterbootstrap analysis of the breakpoint analysis revealed that the 1970s, and to some degree the 1990s, were periods of higher than average probability of a state change in the interspecific A-O relationship. Further, a species risk assessment combining life history derived measures of population resilience and the potential of hyper-stability was developed.

Blackburn et al. (2006) carried out a meta-analysis to study the strength (effect size) of 279 published interspecific A-O relationships. They found that effect size was strongest for taxa in marine and intertidal realms, intermediate for terrestrial and lowest for freshwater taxa. However, only 11 marine (incl. 9 for fish) and 12 intertidal relationships were included in the meta-analysis, while there were 82 for birds. In the present study, focused on Georges Bank, intraspecific A-O relationships were positive (all slopes significantly larger than zero) for all 32 studied species. The strength of the relationship $\left(r^{2}\right)$ varied between 0.09 and 0.84 , corresponding to effect sizes of 0.3-1.6, which are well within the range of those found by Blackburn et al. (2006). These results are somewhat in disagreement with earlier work on Georges Bank for seven species studied here. For these seven species, Murawski and Finn (1988) documented positive non-significant relationships between distribution and abundance, depending on the age category considered. Reanalyzing these cases, Marshall and Frank (1994) found that the relationships depended critically on which indices were used for abundance and occupancy. Murawski and Finn (1988) used a different index of occupancy and most importantly, only 24 years of data were available, while here we benefited from a further 20 years of data collection. More data points (years) means a wider range of abundance and occupancy values and larger power in any statistical test. Thus, differences could be due to statistical power.

Temporal changes in A-O relationships have been rarely studied, and mainly for avian species (Zuckerberg et al. 2009), but there is a notable study on demersal fish (Fisher and Frank 2004). Zuckerberg et al. (2009) found that the A-O relationship derived from the New York Breeding Birds Atlas was stable for two time periods. In contrast, for fish on the Scotian Shelf, the slopes 
of the A-O relationship decreased steadily over 32 years (Fisher and Frank 2004), which is what we found for the Georges Bank fish community. Fisher and Frank (2004) explained the observation of decreasing slope values by two mechanisms: (1), predation release of small abundant species due to selective fishing of larger predators that effectively increased the density of small individuals leading to a proportionally greater increase in abundance compared to occupancy; and (2), a shift in target species to rarer species that decreased their abundance and had relatively less impact on their occupancy. As a result, the A-O curve became flatter and the slope values smaller. In order for the impact of selective fishing to be considered as an explanation, species that are changing abundance, in particular the abundant ones, must disperse little after the abundance change, otherwise the original A-O relationship would be maintained. Thus, reduced dispersal capacity is probably an important explanatory factor, as suggested by Blackburn et al. (2006).

Positive interspecific A-O relationships were found for all years. The slopes $s$ and strengths $\left(r^{2}\right)$ of these relationships showed significant decreases over the study period. Both were positively correlated with total landings for the bottom trawl fishery on Georges Bank. A notable finding is that during the period of 1963-1972 breakpoint analysis indicated that this period was significantly different from the rest of the time series with a propensity for individuals of all species to be found in more locations for the same level of abundance. One possible explanation is that after this period, optimal habitat was located in a more restricted area leading to increased aggregation. This could result from a decline in suitable habitat or fragmentation of habitat leading to decreased dispersal, as found for birds (Freckelton et al. 2006). The decreasing quality of the A-O fit over time is consistent with the hypothesis of habitat fragmentation. Other possible explanations include species abundance and distributional changes (Fisher and Frank 2004). In either case fishing might have played an important role.

During the 1960s and early 1970s commercial landings were at historic highs with the U.S. and distant-water fleets harvesting large quantities of pelagics, flounders, principal groundfish and small elasmobranchs (Fogarty and Murawski 1998; Sosebee and Cadrin 2006). During this period, groundfish and flounders were decreasing while small elasmobranchs and pelagics were at their lowest biomass levels for the time series (Fogarty and Murawski 1998, Sosebee and Cadrin 2006). The macroecological structure responded with rapid declines in the slopes (s) and strengths $\left(r^{2}\right)$ of the interspecific A-O relationship. The breakpoint analysis showed that 1973 was the year when trends in the slopes of A-O relationships changed from a sharp decline to a relatively shallow decline over time, i.e. that occupancy was decreasing for any given level of abundance. The species jackknife analysis of the breakpoint showed individual species did not have a notable impact on the breakpoint period suggesting that the changes were broadly based in the Georges Bank fish community. These changes in the community A-O relationship in 1973 likely result from a combined effect of changes in fisheries landings, fisheries management, habitat availability, and environmental conditions affecting community productivity.

Following this period Georges Bank entered a new exploitation regime beginning in 1976 that was characterized by reduced fishing effort and harvest compared to the 1960s and early 1970s (Fogarty and Murawski 1998, Sosebee and Cadrin 2006). Changes in the macroecological patterns following 1976 were less drastic but declines in the values for the slope (s) and strength of the A-O relationships continued at lower rates (Figure 2). Clearly, the changes in harvest and associated community changes have the potential to impact the interspecific A-O relationship. Investigating this potential, landings data were found to be significantly associated with the slopes $(s)$ and strengths $\left(r^{2}\right)$ of the interspecific A-O relationships suggesting a causal link, either direct or via a common third variable. 
Given the link with exploitation, the slopes of the intra- and interspecific A-O relationships could be used in several ways for management. As demonstrated here, the inverse of the slope for intraspecific relationships might be used as a measure of catchability, which in combination with a measure of resilience allowed us to rank species in terms of the relative risk of overexploitation. Thus, the aggregation pattern as expressed in the slope of the intraspecific A$O$ relationship could be added to the list of life history traits commonly used to characterize the sensitivity of species to fishing, e.g. Jennings et al. 1999. On the assemblage level, the time trend in the slope of the A-O relationship could be used as an indicator for changes in assemblage structure, with decreasing time trends implying an increasingly perturbed system. Thus the slope of the interspecific A-O relationship might join the list of indicators suitable for determining the impact of fishing on exploited communities (Rochet and Trenkel 2003).

We used interspecific A-O relationships to measure community structural change over time assuming a log-linear model captures the positive nature of relationships. We chose the current model structure because the functional form matched theoretical considerations and provided the same information that three parameter A-O models provided with less correlation between parameters. We feel the model we presented captures the A-O relationship well without restrictive assumptions allowing for the detection of temporal trends and development of hypotheses linking physical and environmental drivers to patterns in the macroecological structure of ecosystems.

The analyses presented herein utilized a long time series of data that the NMFS collects to support stock assessments and related research. We utilized the time series to analyze both individual and multi-species spatial patterns. Our approach provided the opportunity to assess the potential impact on the community assemblage structure resulting from habitat alteration in a system where it is difficult to directly quantify habitat change. This provides a powerful approach for addressing macroecological questions in marine ecosystems; but it is not without uncertainties. An assumption of interspecific analysis is that shifts in the most abundant species will not significantly impact resulting relationships. We did not find evidence that this was occurring in our system but it remains a possible source of uncertainty. Further, the research only considers Georges Bank and species migration to and from the study area (Frisk et al. 2008) and climate induced distributional changes in species ranges (Nye et al. 2009) were not directly considered.

The approach also allowed the ranking of species vulnerability to exploitation in terms of the risk of hyper-stability $(\Delta q)$ and a life history derived resiliency measure providing needed information to managers for both exploited and understudied non-commercial species. The combination of high $\Delta q$ and low resilience was observed for a number of species including: blackbelly rosefish, pollock, witch flounder, and spiny dogfish. Blackbelly rosefish and spiny dogfish are both species that would be expected to be on the top of any list of species sensitive to exploitation. On the other hand, the life histories of pollock, Atlantic herring, and Atlantic mackerel suggest they should fare well under exploitation with resilience scores of 2 or less. However, these three species all have increased risk of hyper-stability and a precautionary approach should be taken when setting exploitation limits, especially if populations have declined. Therefore, in addition to traditional vulnerability rankings derived from life history alone, indicators that include the interaction of the spatial patterns of species and behaviour of fishing fleets should be utilized. 


\section{Acknowledgments}

This research was initiated as part of the work conducted by members of the International Council for the Exploration of the Sea (ICES) Working Group on Fish Ecology (WGFE) in the spring of 2007 and 2008. We would like to thank the members of WGFE for support, review and assistance on this research. Participation of M.G. Frisk in WGFE was supported through Drs. John H. Steele and Edward D. Houde and NSF Grant \#OCE-0738214. The work of V.T. was partially funded by the EU project IMAGE (contract FP6 - 044227). Further, we thank members of the Frisk lab and Drs. A. Jordaan and J.A. Nye for editorial comments.

\section{References}

Anderson, J. T., and G. A. Rose. 2001. Offshore spawning and year-class strength of northern cod (2J3KL) during the fishing moratorium, 1994-1996. Canadian Journal of Fisheries and Aquatic Sciences 58:1386-1394.

Blackburn, T. M., P. Cassey, and K. J. Gaston. 2006. Variations on a theme: sources of heterogeneity in the form of the interspecific relationship between abundance and distribution. Journal of Animal Ecology 75:1426-1439.

Carpenter, S. R., J. J. Cole, J. R. Hodgson, J. F. Kitchell, M. L. Pace, D. Bade, K. L. Cottingham, T. E. Essington, J. N. Houser, and D. E. Schindler. 2001. Trophic cascades, nutrients, and lake productivity: whole-lake experiments. Ecological Monographs 71:163186.

Cingolani, A. M., I. Noy-Meir, and S. Diaz. 2005. Grazing effects on rangeland diversity: A synthesis of contemporary models. Ecological Applications 15:757-773.

Collie, J. S., K. Richardson, and J. H. Steele. 2004. Regime shifts: can ecological theory illuminate the mechanisms? Progress in Oceanography 60:281-302.

Donovan, T. M., and C. H. Flather. 2002. Relationships among north American songbird trends, habitat fragmentation, and landscape occupancy. Ecological Applications 12:364-374.

Ellis, N., and Y. G. Wang. 2007. Effects of fish density distribution and effort distribution on catchability. Ices Journal of Marine Science 64:178-191.

Fisher, J. A. D., and K. T. Frank. 2004. Abundance-distribution relationships and conservation of exploited marine fishes. Marine Ecology-Progress Series 279:201-213.

Fogarty, M. J., and S. A. Murawski. 1998. Large-scale disturbance and the structure of marine system: Fishery impacts on Georges Bank. Ecological Applications 8:S6-S22.

Freckleton, R. P., D. Noble, and T. J. Webb. 2006. Distributions of habitat suitability and the abundance-occupancy relationship. American Naturalist 167:260-275.

Frisk, M. G., T. J. Miller, S. J. D. Martell, and K. Sosebee. 2008. New hypothesis helps explain elasmobranch "OutBurst" on Georges bank in the 1980s. Ecological Applications 18:234-245.

Fuller, T. L., D. R. Foster, T. S. McLachlan, and N. Drake. 1998. Impact of human activity on regional forest composition and dynamics in central New England. Ecosystems 1:76-95.

Gaston, K. J., T. M. Blackburn, J. J. D. Greenwood, R. D. Gregory, R. M. Quinn, and J. H. Lawton. 2000. Abundance-occupancy relationships. Journal of Applied Ecology 37:3959.

Holt, A. R., P. H. Warren, and K. J. Gaston. 2002. The importance of biotic interactions in abundance-occupancy relationships. Journal of Animal Ecology 71:846-854. 
Holt, R.D., Lawton, J.H., Gaston, K.J., and Blackburn, T.M. 1997. On the relationship between range size and local abundance: Back to basics. Oikos 78(1): 183-190.

Huse, G., S. Railsback, and A. Ferno. 2002. Modelling changes in migration pattern of herring: collective behaviour and numerical domination. Journal of Fish Biology 60:571-582.

Hutchings, J. A. 1996. Spatial and temporal variation in the density of northern cod and a review of hypotheses for the stock's collapse. Canadian Journal of Fisheries and Aquatic Sciences 53:943-962.

ICES. 2007. Report of the workshop on testing the entrainment hypothesis (WKTEST). ICES CM 2007/LRC:10.

Jennings, S., S. P. R. Greenstreet, and J. D. Reynolds. 1999. Structural change in an exploited fish community: a consequence of differential fishing effects on species with contrasting life histories. Journal of Animal Ecology 68:617-627.

MacCall, A.D. 1990. Dynamic geography of marine fish populations. University of Washington, Seattle, Washington. P. 153.

Mangel, M., and P. S. Levin. 2005. Regime, phase and paradigm shifts: making community ecology the basic science for fisheries. Philosophical Transactions of the Royal Society B-Biological Sciences 360:95-105.

Marshall, C. T., and K. T. Frank. 1994. Geographic responses of groundfish to variation in abundance - Methods of detection and their interpretation. Canadian Journal of Fisheries and Aquatic Sciences 51:808-816.

McGowan, S., P. R. Leavitt, R. I. Hall, N. J. Anderson, E. Jeppesen, and B. V. Odgaard. 2005. Controls of algal abundance and community composition during ecosystem state change. Ecology 86:2200-2211.

Murawski, S. A., and J. T. Finn. 1988. Biological bases for mixed-species fisheries - Species codistribution in relation to environmental and biotic variables Canadian Journal of Fisheries and Aquatic Sciences 45:1720-1735.

Musick, J. A. 1999. Criteria to define extinction risk in marine fishes - The American Fisheries Society initiative. Fisheries 24:6-14.

Myers, R. A., and B. Worm. 2005. Extinction, survival or recovery of large predatory fishes. Philosophical Transactions of the Royal Society B-Biological Sciences 360:13-20.

Nye, J. A., J. S. Link, J. A. Hare, and W. J. Overholtz. 2009. Changing spatial distribution of fish stocks in relation to climate and population size on the Northeast United States continental shelf. Marine Ecology-Progress Series 393:111-129.

Nystrom, M., C. Folke, and F. Moberg. 2000. Coral reef disturbance and resilience in a humandominated environment. Trends in Ecology and Evolution 15:413-417.

Ottersen, G., B. Planque, A. Belgrano, E. Post, P. C. Reid, and N. C. Stenseth. 2001. Ecological effects of the North Atlantic Oscillation. Oecologia 128:1-14.

Rochet, M.-J., and V. M. Trenkel. 2003. Which community indicators can measure the impact of fishing: A review and proposals. Canadian Journal of Fisheries and Aquatic Sciences 60:86-99.

Scheffer, M., S. Carpenter, J. A. Foley, C. Folke, and B. Walker. 2001. Catastrophic shifts in ecosystems. Nature 413:591-596.

Sosebee, K. A., and S. X. Cadrin. 2006. Historical perspectives on the abundance and biomass of some northeast demersal finfish stocks from NMFS and Massachusetts inshore bottom trawl surveys, 1963-2002. U.S. Department of Commerce, Northeast Fisheries Science Center, Reference Document 00-03.

Swain, D. P., and A. F. Sinclair. 1994. Fish distribution and catchability - What is the appropriate measure of distribution. Canadian Journal of Fisheries and Aquatic Sciences 51:10461054.

van Langevelde, F., C. van de Vijver, L. Kumar, J. van de Koppel, N. de Ridder, J. van Andel, A. K. Skidmore, J. W. Hearne, L. Stroosnijder, W. J. Bond, H. H. T. Prins, and M. 
Rietkerk. 2003. Effects of fire and herbivory on the stability of savanna ecosystems. Ecology 84:337-350.

Webb, T. J., D. Noble, and R. P. Freckleton. 2007. Abundance-occupancy dynamics in a human dominated environment: linking interspecific and intraspecific trends in British farmland and woodland birds. Journal of Animal Ecology 76:123-134.

Zuckerberg, B., W. F. Porter, and K. Corwin. 2009. The consistency and stability of abundance- occupancy relationships in large-scale population dynamics. Journal of Animal Ecology 78:172-181.

\section{Tables}

TABLE 1. Results of the intraspecific model fits for Georges Bank finfish and shellfish including intercept $(C)$, slope $(s), r^{2}, P$ value, $\Delta q$, and resilience (1 [very high] to 4 [very low]).

\begin{tabular}{|c|c|c|c|c|c|c|c|}
\hline $\begin{array}{l}\text { Common } \\
\text { name }\end{array}$ & $\begin{array}{l}\text { Scientific } \\
\text { name }\end{array}$ & Intercept & Slope & $r^{2}$ & $P$ & $\Delta q$ & Resilience \\
\hline Acadian redfish & Sebastes fasciatus & 0.117 & 0.023 & 0.290 & 0.000 & 43.73 & 3 \\
\hline American lobster & Homarus americamus & 0.395 & 0.177 & 0.539 & 0.000 & 5.65 & \\
\hline American plaice & Hippoglossoides platessoides & 0.144 & 0.083 & 0.408 & 0.000 & 12.04 & 2 \\
\hline Atlantic cod & Gadus morhua & 0.227 & 0.112 & 0.425 & 0.000 & 8.95 & 2 \\
\hline Atlantic herring & Clupea harengus harengus & 0.179 & 0.038 & 0.502 & 0.000 & 26.14 & 2 \\
\hline Atlantic mackerel & Scomber scombrus & 0.147 & 0.033 & 0.654 & 0.000 & 30.09 & 2 \\
\hline Blackbelly rosefish & Helicolemus dactylopterus dactylopterus & 0.115 & 0.023 & 0.257 & 0.001 & 44.16 & 4 \\
\hline Butterfish & Peprilus triacanthus & 0.216 & 0.076 & 0.452 & 0.000 & 13.12 & 1 \\
\hline Fawn cusk-eel & Lepophidium profundorum & 0.103 & 0.023 & 0.580 & 0.000 & 43.37 & 1 \\
\hline Fourspot flounder & Hippoglossina oblonga & 0.286 & 0.110 & 0.600 & 0.000 & 9.08 & 2 \\
\hline Gulf stream flounder & Citharichthys arctifrons & 0.152 & 0.033 & 0.447 & 0.000 & 30.30 & 1 \\
\hline Haddock & Melanogrammus aeglefinus & 0.240 & 0.070 & 0.298 & 0.000 & 14.28 & 2 \\
\hline Little skate & Leucoraja erinacea & 0.347 & 0.131 & 0.339 & 0.000 & 7.63 & 3 \\
\hline Longfin squid & Loligo pealeii & 0.160 & 0.083 & 0.595 & 0.000 & 12.03 & \\
\hline Longhorn sculpin & Myoxocephalus octodecemspinosus & 0.440 & 0.048 & 0.093 & 0.044 & 20.66 & 3 \\
\hline Moustache sculpin & Triglops murrayi & 0.098 & 0.025 & 0.410 & 0.000 & 40.21 & 3 \\
\hline Northern sand lance & Ammodytes dubius & 0.156 & 0.038 & 0.721 & 0.000 & 26.08 & 2 \\
\hline Northern shortfin squid & Illex illecebrosus & 0.395 & 0.145 & 0.844 & 0.000 & 6.90 & \\
\hline Ocean pout & Zoarces americanus & 0.226 & 0.064 & 0.560 & 0.000 & 15.70 & 3 \\
\hline Pollock & Pollachius virens & 0.119 & 0.016 & 0.216 & 0.002 & 62.22 & 2 \\
\hline Red hake & Urophycis chuss & 0.312 & 0.086 & 0.406 & 0.000 & 11.58 & 2 \\
\hline Sea raven & Hemitripterus americanus & 0.351 & 0.136 & 0.312 & 0.000 & 7.36 & \\
\hline Sea scallop & Placopecten magellanicus & 0.176 & 0.063 & 0.699 & 0.000 & 15.76 & \\
\hline Silver hake & Merluccius bilinearis & 0.583 & 0.056 & 0.220 & 0.001 & 18.01 & 2 \\
\hline Spiny dogfish & Squalus acanthias & 0.234 & 0.072 & 0.488 & 0.000 & 13.93 & $\overline{4}$ \\
\hline Thorny skate & Amblyraja radiata & 0.239 & 0.103 & 0.607 & 0.000 & 9.74 & 3 \\
\hline White hake & Urophycis temuis & 0.253 & 0.114 & 0.605 & 0.000 & 8.79 & 3 \\
\hline Windowpane & Scophthalmus aquosus & 0.208 & 0.068 & 0.455 & 0.000 & 14.74 & 2 \\
\hline Winter flounder & Pseudopleuronectes americamus & 0.232 & 0.083 & 0.483 & 0.000 & 12.08 & $\overline{2}$ \\
\hline Winter skate & Leucoraja ocellata & 0.390 & 0.092 & 0.296 & 0.000 & 10.83 & 3 \\
\hline Witch flounder & Glyptocephalus cynoglossus & 0.142 & 0.033 & 0.497 & 0.000 & 29.87 & 3 \\
\hline Yellowtail flounder & Limanda ferruginea & 0.270 & 0.092 & 0.747 & 0.000 & 10.88 & 1 \\
\hline
\end{tabular}

Notes: Resilience estimates were based on biological parameters (growth rate, age at maturity, and life span) and provided a measure of productivity in the following categories: high (von Bertalanffy growth coefficient $[k]>0.3 \mathrm{yr}^{-1}$, age at maturity $\left[t_{\mathrm{mat}}\right]<$ $1 \mathrm{yr}$, longevity $\left.\left[t_{\max }\right]=1-3 \mathrm{yr}\right)$, medium $\left(k=0.16-0.30, t_{\mathrm{mat}}=2-4, t_{\max }=4-10\right)$, low $\left(k=0.05-0.15, t_{\operatorname{mat}}=5-10, t_{\max }=11-30\right)$, and very low $\left(k<0.05, t_{\text {mat }}>10, t_{\max }>30\right)$ (Musick 1999; see also footnote 5). Delta $q$ is a measure of a species' potential of hyperstability, where catch rates will remain high as the population declines. 
TABLE 2. Interspecific abundance-occupancy (A-O) relationships for the Georges Bank finfish and shellfish assemblage were estimated for each year to estimate the intercept, slope, and strength $\left(r^{2}\right)$ of the fits.

\begin{tabular}{|c|c|c|c|}
\hline Year & Intercept & Slope & $r^{2}$ \\
\hline 1963 & 0.319 & 0.125 & 0.617 \\
\hline 1964 & 0.249 & 0.106 & 0.650 \\
\hline 1965 & 0.275 & 0.116 & 0.736 \\
\hline 1966 & 0.284 & 0.109 & 0.614 \\
\hline 1967 & 0.305 & 0.092 & 0.612 \\
\hline 1968 & 0.270 & 0.111 & 0.714 \\
\hline 1969 & 0.261 & 0.090 & 0.671 \\
\hline 1970 & 0.269 & 0.107 & 0.743 \\
\hline 1971 & 0.258 & 0.096 & 0.593 \\
\hline 1972 & 0.204 & 0.124 & 0.703 \\
\hline 1973 & 0.256 & 0.105 & 0.658 \\
\hline 1974 & 0.232 & 0.087 & 0.676 \\
\hline 1975 & 0.247 & 0.067 & 0.481 \\
\hline 1976 & 0.264 & 0.089 & 0.686 \\
\hline 1977 & 0.242 & 0.093 & 0.532 \\
\hline 1978 & 0.196 & 0.097 & 0.539 \\
\hline 1979 & 0.250 & 0.103 & 0.762 \\
\hline 1980 & 0.240 & 0.086 & 0.462 \\
\hline 1981 & 0.261 & 0.071 & 0.483 \\
\hline 1982 & 0.244 & 0.088 & 0.691 \\
\hline 1983 & 0.255 & 0.071 & 0.758 \\
\hline 1984 & 0.261 & 0.092 & 0.770 \\
\hline 1985 & 0.230 & 0.079 & 0.753 \\
\hline 1986 & 0.216 & 0.085 & 0.592 \\
\hline 1987 & 0.237 & 0.087 & 0.594 \\
\hline 1988 & 0.218 & 0.087 & 0.619 \\
\hline 1989 & 0.242 & 0.086 & 0.652 \\
\hline 1990 & 0.222 & 0.085 & 0.535 \\
\hline 1991 & 0.247 & 0.079 & 0.620 \\
\hline 1992 & 0.243 & 0.082 & 0.644 \\
\hline 1993 & 0.218 & 0.070 & 0.376 \\
\hline 1994 & 0.227 & 0.091 & 0.599 \\
\hline 1995 & 0.208 & 0.081 & 0.485 \\
\hline 1996 & 0.257 & 0.075 & 0.504 \\
\hline 1997 & 0.230 & 0.086 & 0.508 \\
\hline 1998 & 0.254 & 0.102 & 0.681 \\
\hline 1999 & 0.230 & 0.078 & 0.530 \\
\hline 2000 & 0.228 & 0.086 & 0.593 \\
\hline 2001 & 0.255 & 0.081 & 0.551 \\
\hline 2002 & 0.230 & 0.086 & 0.516 \\
\hline 2003 & 0.232 & 0.073 & 0.447 \\
\hline 2004 & 0.257 & 0.085 & 0.568 \\
\hline 2005 & 0.248 & 0.087 & 0.450 \\
\hline 2006 & 0.234 & 0.079 & 0.609 \\
\hline
\end{tabular}

Note: All years were significant at $P=0.00001$. 
TABLE 3. Estimates of the correlation of abundance and time and the correlation of percentage occupancy and time, where "Corr." is the Spearman's rank correlation and "D-W" is the Durbin-Watson statistic.

\begin{tabular}{|c|c|c|c|c|c|c|c|c|}
\hline \multirow{2}{*}{$\begin{array}{c}\text { Common } \\
\text { name }\end{array}$} & \multirow{2}{*}{$\begin{array}{l}\text { Species } \\
\text { name }\end{array}$} & \multirow[b]{2}{*}{ Group } & \multicolumn{3}{|c|}{ Abundance } & \multicolumn{3}{|c|}{ Occupancy } \\
\hline & & & Corr. & $P$ & D-W & Corr. & $P$ & D-W \\
\hline Acadian redfish & Sebastes fasciatus & others & -0.289 & 0.058 & & -0.291 & 0.055 & \\
\hline American lobster & Homarus americanus & & 0.216 & 0.158 & & 0.449 & $0.002 *$ & \\
\hline American plaice & $\begin{array}{l}\text { Hippoglossoides } \\
\text { platessoides }\end{array}$ & flatfish & -0.177 & 0.250 & & -0.317 & $0.036^{*}$ & \\
\hline Atlantic cod & Gadus morhua & gadoids & -0.459 & $0.002^{*}$ & & -0.693 & $<0.0001 * * * *$ & \\
\hline Atlantic herring & $\begin{array}{l}\text { Clupea harengus } \\
\text { harengus }\end{array}$ & pelagics & 0.636 & $<0.0001^{* * * *}$ & & 0.202 & 0.189 & \\
\hline Atlantic mackerel & Scomber scombrus & pelagics & 0.397 & $0.008 * *$ & & 0.287 & 0.059 & \\
\hline Blackbelly rosefish & $\begin{array}{l}\text { Helicolenus } \\
\text { dactylopterus } \\
\text { dactylopterus }\end{array}$ & others & -0.053 & 0.733 & & -0.164 & 0.288 & \\
\hline Butterfish & Peprilus triacanthus & others & 0.479 & $0.001^{* * *}$ & & 0.428 & $0.004 * *$ & \\
\hline Fawn cusk-eel & $\begin{array}{l}\text { Lepophidium } \\
\text { profundorum }\end{array}$ & others & 0.345 & $0.022^{*}$ & & 0.089 & 0.567 & \\
\hline Fourspot flounder & Hippoglossina oblonga & flatfish & 0.750 & $<0.0001^{* * * *}$ & & 0.600 & $<0.0001 * * * *$ & 1.364 \\
\hline Gulf stream flounder & Citharichthys arctifrons & flatfish & 0.318 & $0.035^{*}$ & & 0.293 & 0.053 & 1.367 \\
\hline Haddock & $\begin{array}{l}\text { Melanogrammus } \\
\text { aeglefinus }\end{array}$ & gadoids & 0.188 & 0.222 & & -0.291 & 0.055 & \\
\hline Little skate & Leucoraja erinacea & elasmobranchs & 0.434 & $0.003^{* *}$ & 1.233 & 0.357 & $0.017^{*}$ & \\
\hline Longfin squid & Loligo pealeii & & 0.476 & $0.001^{* * *}$ & & 0.398 & $0.008 * *$ & 1.024 \\
\hline Longhom sculpin & $\begin{array}{l}\text { Myoxocephalus } \\
\text { octodecemspinosus }\end{array}$ & others & 0.398 & $0.007^{* *}$ & & -0.293 & 0.054 & \\
\hline Moustache sculpin & Triglops murrayi & others & -0.271 & 0.076 & & -0.457 & $0.002 * *$ & \\
\hline Northern sand lance & Ammodytes dubius & others & 0.294 & 0.053 & & 0.282 & 0.064 & \\
\hline Northern shortfin squid & Illex illecebrosus & & 0.446 & $0.002 * *$ & 1.087 & 0.461 & $0.002 * *$ & 0.614 \\
\hline Ocean pout & Zoarces americamus & others & 0.153 & 0.321 & & 0.007 & 0.962 & \\
\hline Pollock & Pollachius virens & gadoids & 0.079 & 0.609 & & -0.289 & 0.057 & \\
\hline Red hake & Urophycis chuss & gadoids & 0.383 & $0.01^{* *}$ & & 0.094 & 0.545 & \\
\hline Sea raven & $\begin{array}{c}\text { Hemitripterus } \\
\text { americanus }\end{array}$ & others & 0.395 & $0.008 * *$ & & -0.127 & 0.410 & \\
\hline Sea scallop & $\begin{array}{l}\text { Placopecten } \\
\text { magellanicus }\end{array}$ & & 0.652 & $<0.0001^{* * * *}$ & & 0.696 & $<0.0001^{* * * *}$ & \\
\hline Silver hake & Merluccius bilinearis & gadoids & 0.542 & $0.0001^{* * * *}$ & & 0.079 & 0.609 & \\
\hline Spiny dogfish & Squalus acanthias & elasmobranchs & 0.299 & $0.048^{*}$ & 1.195 & 0.191 & 0.214 & \\
\hline Thorny skate & Amblyraja radiata & elasmobranchs & -0.681 & $<0.0001^{* * * *}$ & 1.074 & -0.840 & $<0.0001^{* * * *}$ & \\
\hline White hake & Urophycis tenuis & gadoids & -0.431 & $0.003^{* *}$ & 1.108 & -0.538 & $0.000^{* * * *}$ & \\
\hline Windowpane & Scophthalmus aquosus & flatfish & 0.403 & $0.007^{* *}$ & 1.227 & 0.229 & 0.135 & \\
\hline Winter flounder & $\begin{array}{l}\text { Pseudopleuronectes } \\
\text { americamus }\end{array}$ & flatfish & 0.203 & 0.186 & & 0.378 & $0.011^{*}$ & \\
\hline Winter skate & Leucoraja ocellata & elasmobranchs & 0.492 & $0.001^{* * *}$ & 0.732 & 0.493 & $0.001 * * *$ & \\
\hline Witch flounder & $\begin{array}{l}\text { Glyptocephalus } \\
\text { cynoglossus }\end{array}$ & flatfish & -0.218 & 0.155 & & -0.388 & $0.009^{* *}$ & \\
\hline Yellowtail flounder & Limanda ferruginea & flatfish & -0.193 & 0.209 & & -0.409 & $0.006^{* *}$ & \\
\hline
\end{tabular}

Note: The D-W statistic is only provided where the first-order autocorrelation is significant.

${ }^{*} P \leq 0.05 ;{ }^{* *} P \leq 0.01 ; * * * P \leq 0.001 ; * * * * P \leq 0.0001$. 


\section{Figures}

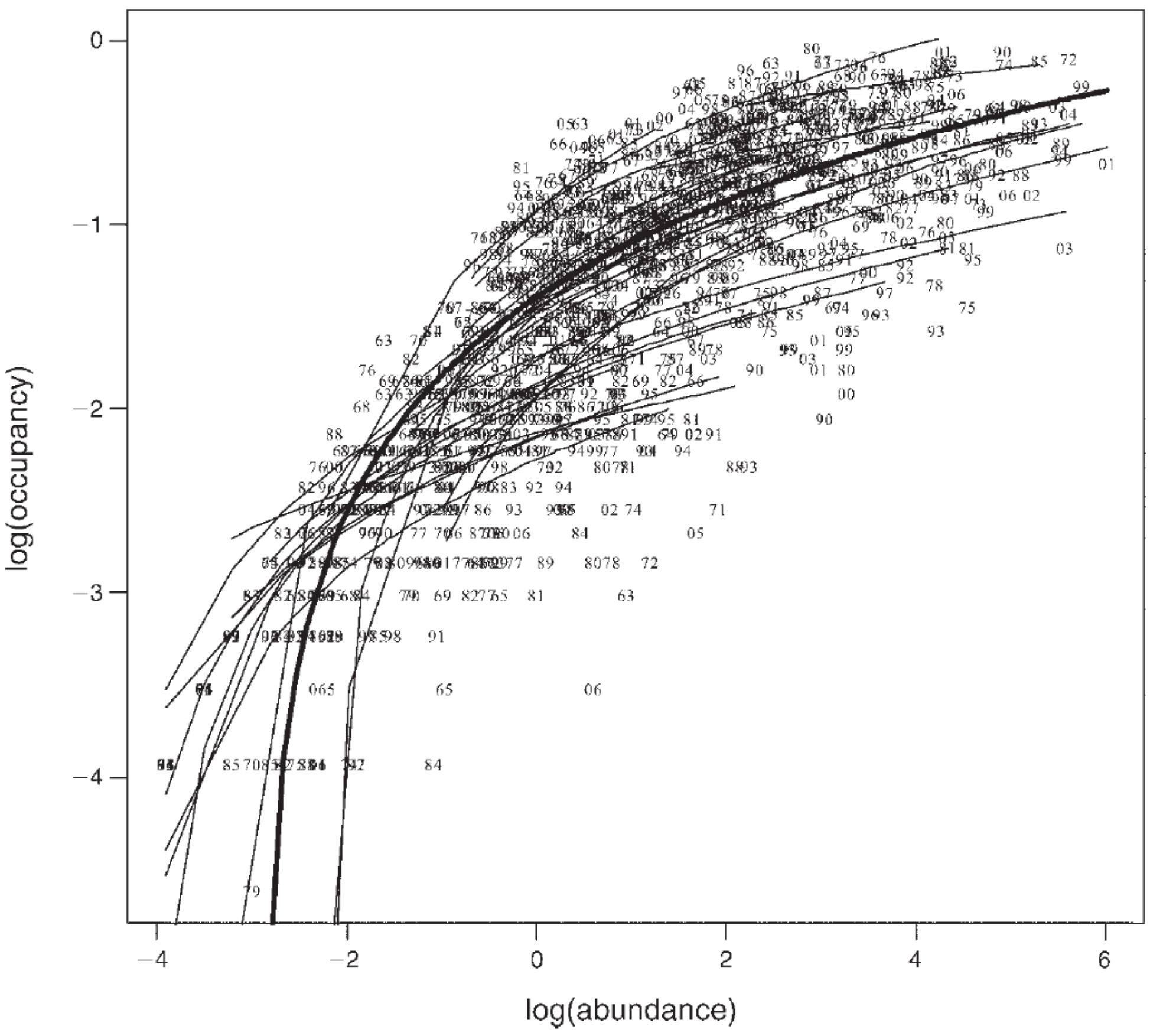

FIG. 1. Intraspecific percentage occupancy regressed against abundance for 32 species on Georges Bank for the autumn survey including finfish, elasmobranchs, lobster, squid, and scallops. Log transformation was performed on percentage occupancy and abundance to enable the display of species that have quite different abundance values on the same plot; however, the fitted models (lines) were occupancy vs. log(abundance) for each species, and the heavy solid line is the global fit to all species and years. Data points are represented by two-digit year designations for the span 1963-2006. 

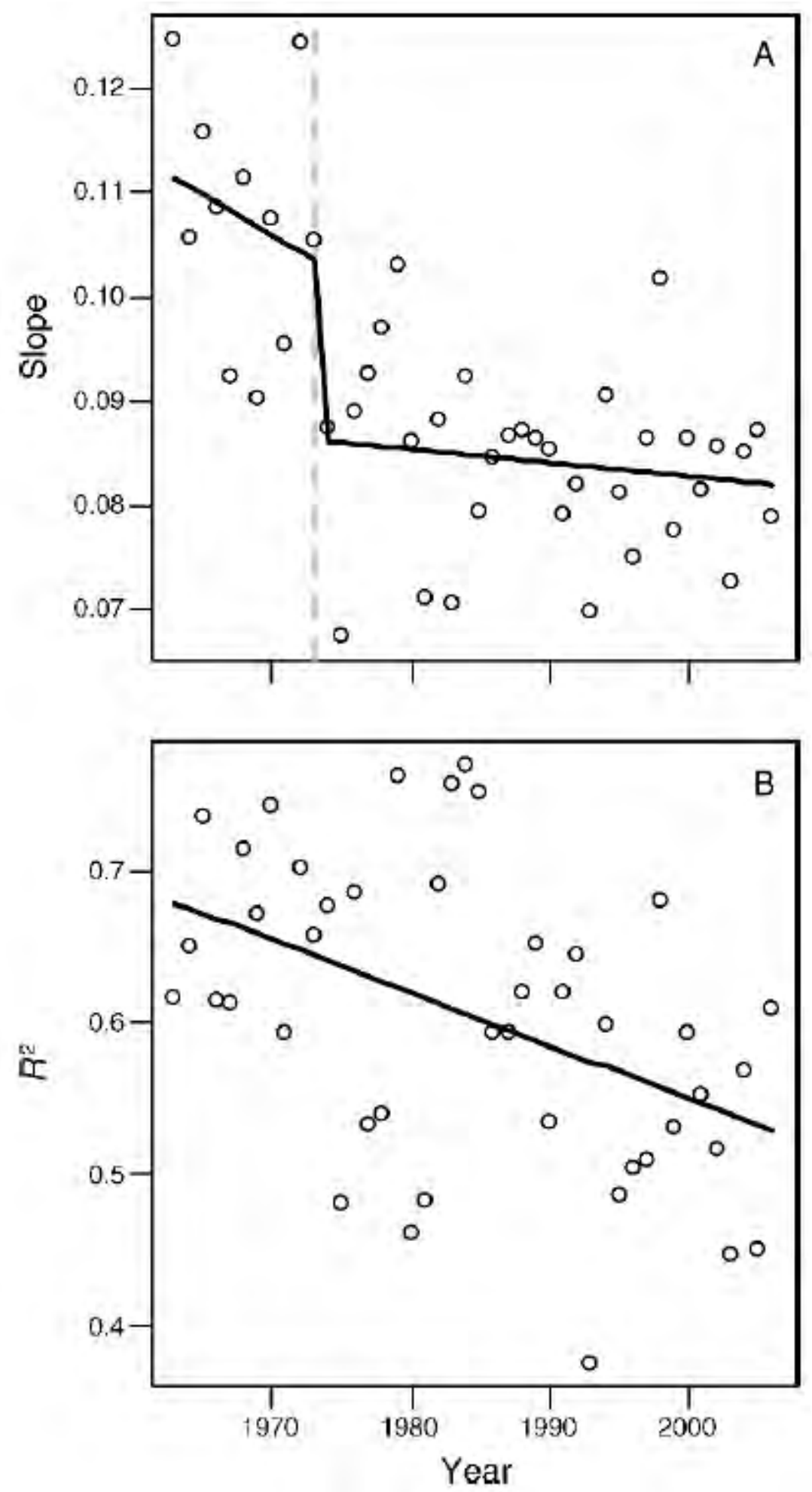

Fig. 2. Breakpoint analysis for the survey with linear trends between break points for the (A) fitted slopes (s) and (B) strengths $\left(r^{2}\right)$ of the interspecific relationships. Break points are depicted only where credible points were found. Breakpoint and segmented regression analysis revealed a single break in the slope in 1973 such that from 1963 to 1973 , the slope steeply declined while after 1973 the slope still declined but at a slower rate. 
Species

Northern shorttin squid

American plaice

Atlantic herring

Acadian redfish

Little skate

Longfin squid

Atlantic mackerel

Gulf Stream flounder

Winter skate

Northern sand lance

Sea raven

Yellowtail flounder

Moustache sculpin

Pollock

Blackbelly rosefish

Silver hake

White hake

Windowpane

Winter flounder

American lobster

Fourspot flounder

Haddock

Ocean pout

Thomy skate

Atlantic cod

Sea scallop

Spiny dogfish

Witch flounder

Fawn cusk-eel

Butterfish

Red hake

Longhorn sculpin
Break point frequency
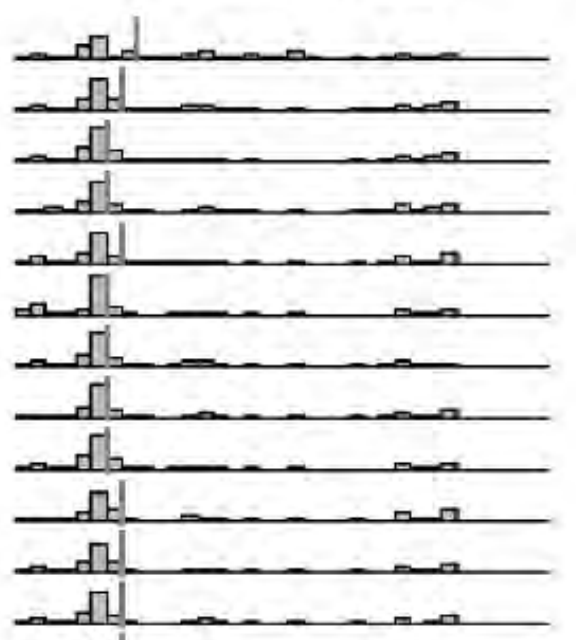

ก.
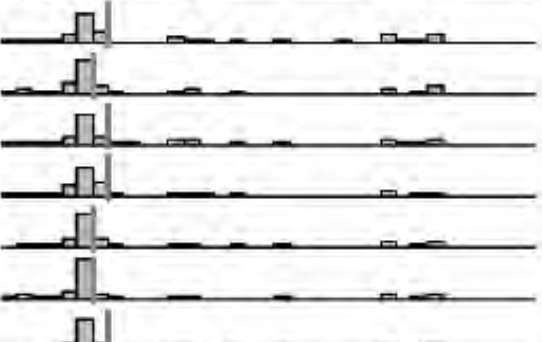

तil

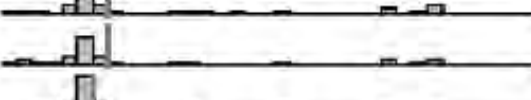

.
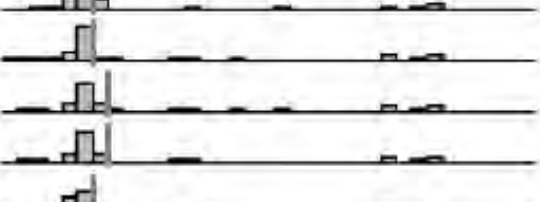

+

단

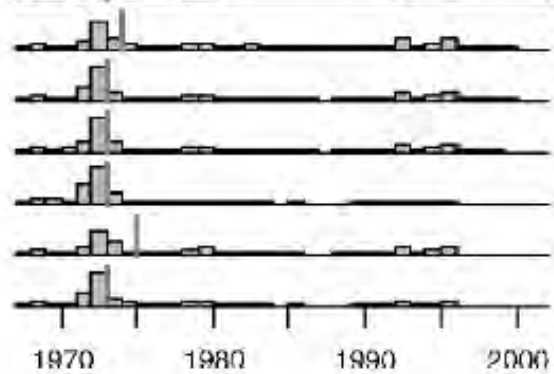

Break point probability

0.29

0.46

0.47

0.48

0.48

0.48

0.50

0.50

0.50

0.51

0.51

0.51

0.52

0.52

0.53

0.55

0.55

0.55

0.55

0.56

0.56

0.56

0.56

0.56

0.57

0.57

0.57

0.57

0.58

0.59

0.59

0.64

FIG. 3. Influence of individual species on the breakpoint year of the slope from a jackknife-after-bootstrap analysis on 40000 resampled data sets. Histograms of breakpoint years over the resampled data sets containing a given species are shown. The median break point is depicted as a vertical line on each histogram. All histograms are on a common scale. The breakpoint probability is the proportion of resampled data sets containing the species that had at least one significant break point. 


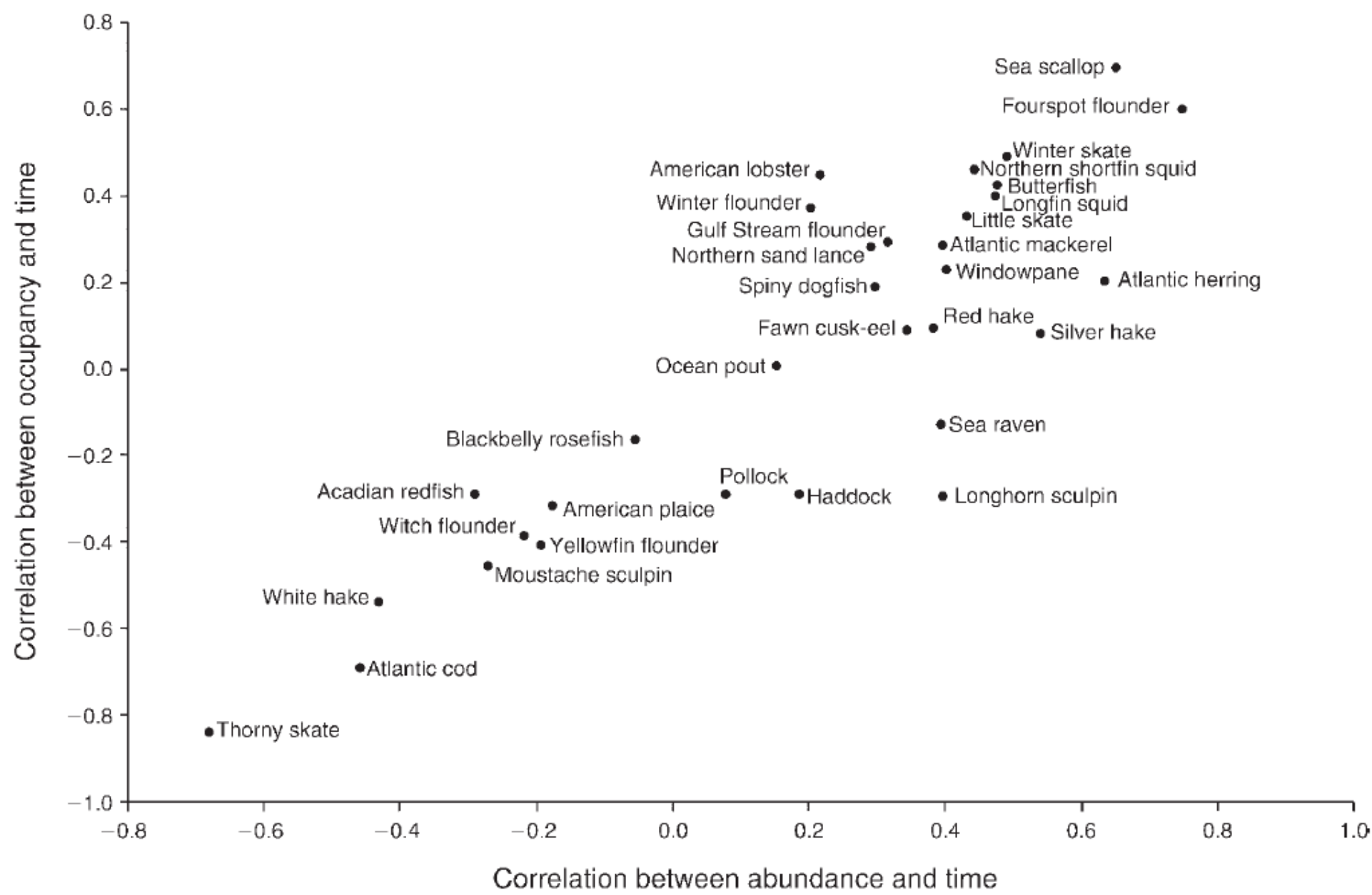

FIG. 4. The relationship between the correlation of percentage occupancy and time and the correlation between abundance and time. Common names are provided adjacent to data points. 


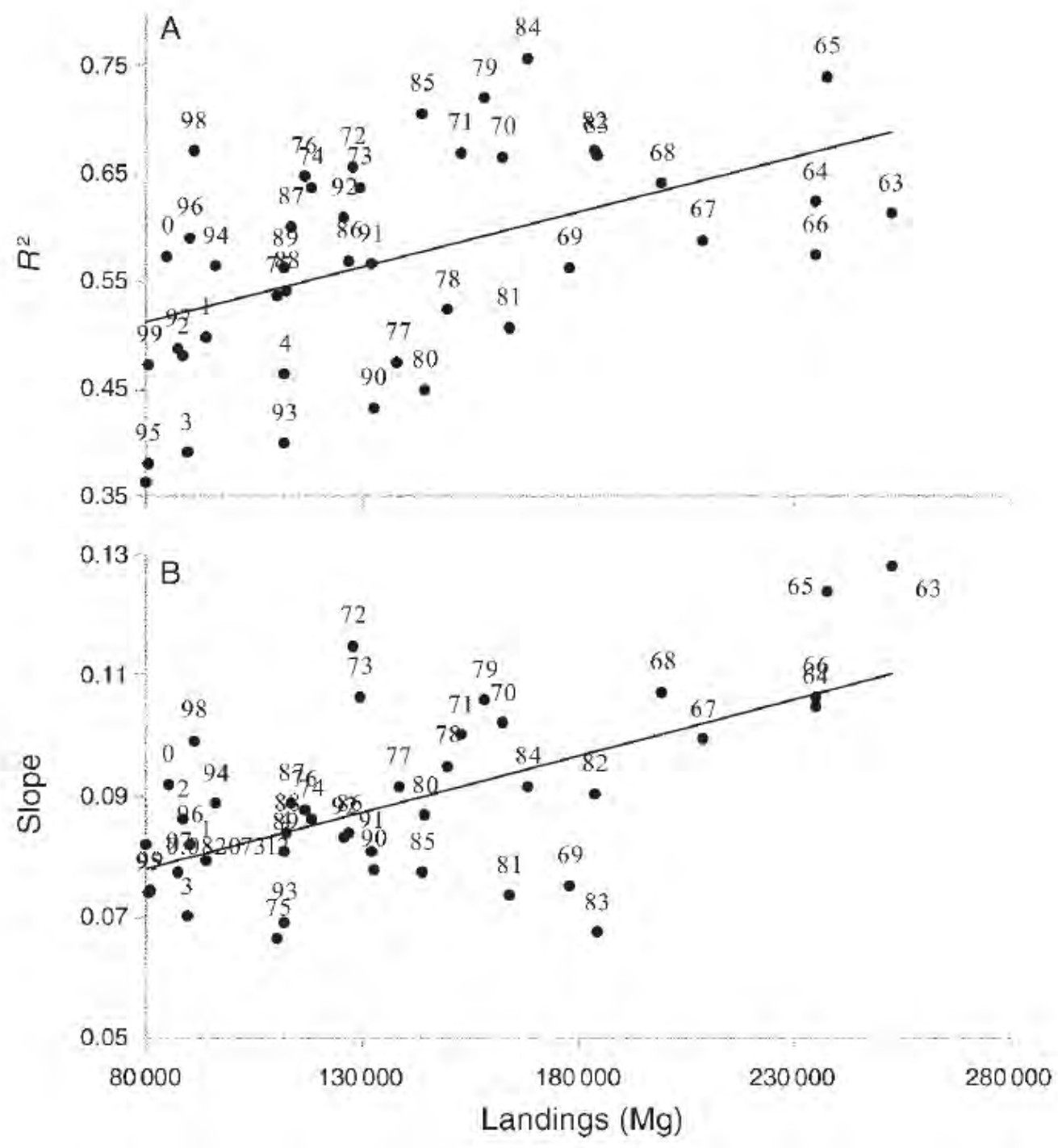

FIG. 5. (A) The relationship of the interspecific $r^{2}$ values vs. landings and (B) the relationship between slope $(s)$ values and landings. Two-digit designations for years are provided above data points for the span 1963-2004. Landings data were obtained from the NOAA Office of Science and Technology for the bottom otter trawl fisheries in the New England region. 


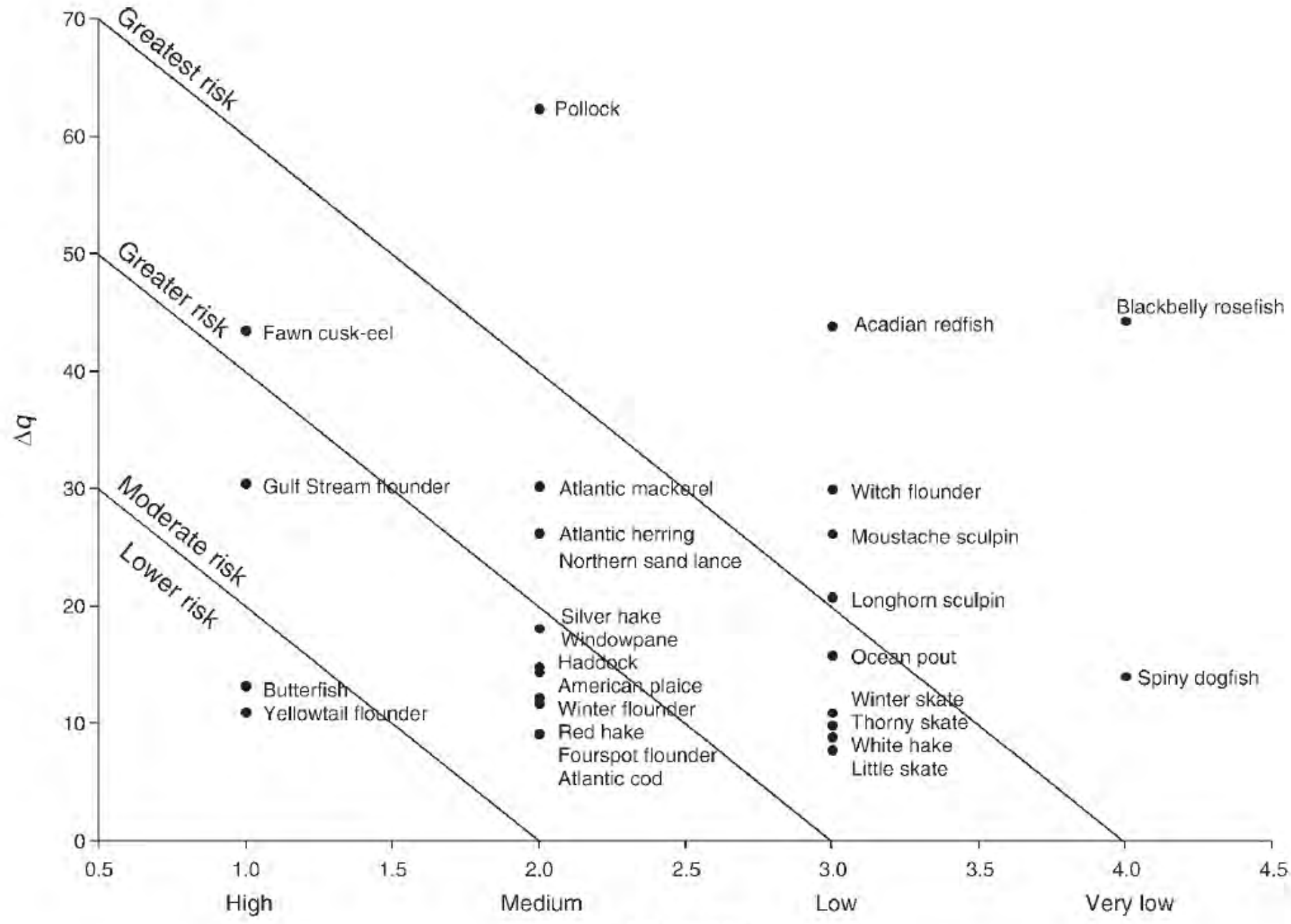

Resilience

FIG. 6. Species' $\Delta q$ and resilience values are plotted to show the relative risk of overexploitation from the combined effects of increases in catchability with declining abundance and slow potential population recovery. Greatest risk was designated for species that could be targeted effectively in aggregation areas and have a slow population turnover rate (resilience: 1 [very high] to 4 [very low]). $\Delta q$ is a measure of a species' potential of hyperstability where catch rates will remain high as the population declines. Note that American lobster, longfin squid, sea raven, and sea scallop lacked resilience estimates and were not included. 


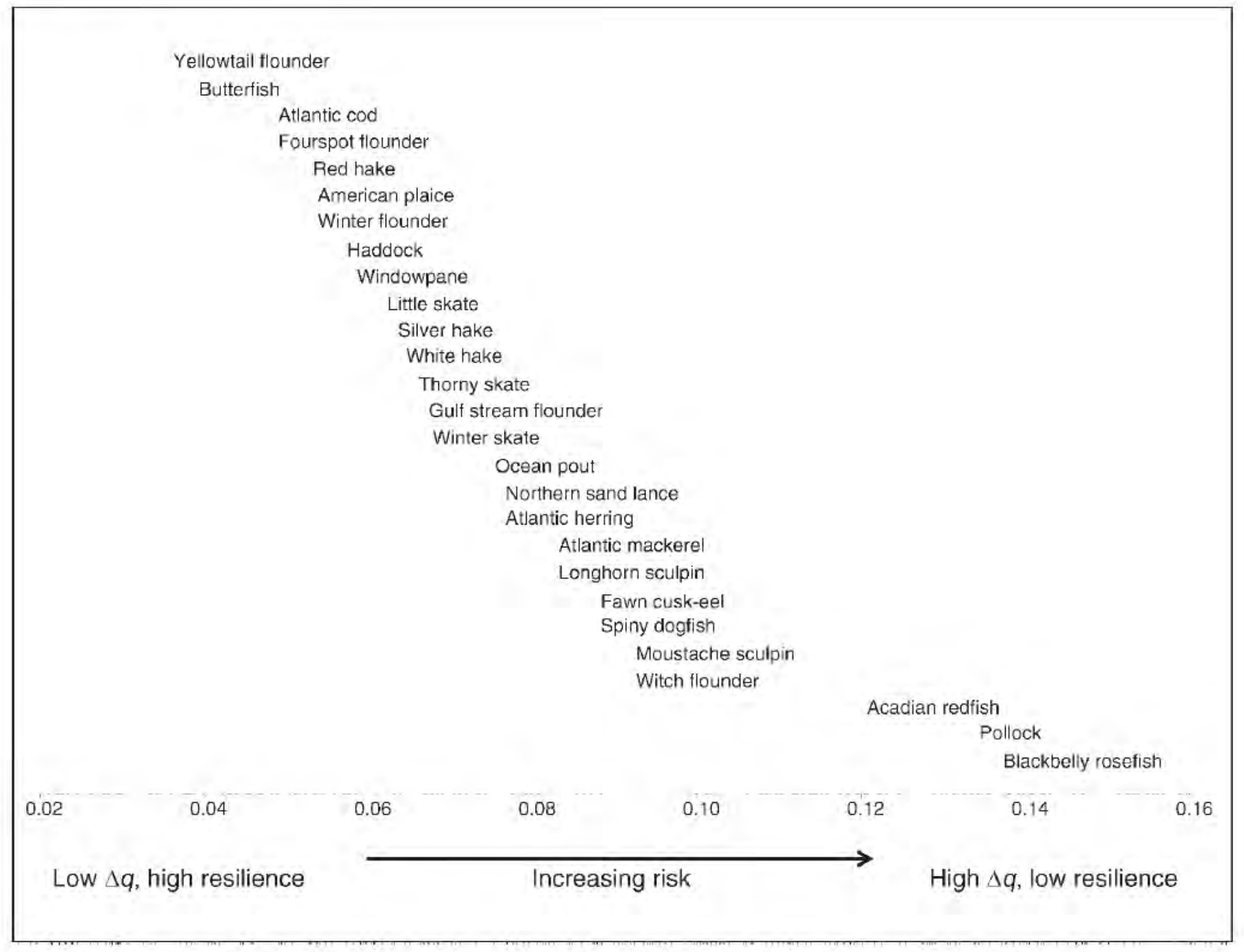

Fig. 7. Species' risk of overexploitation rankings based on standardized $\Delta q$ and population resilience values, where larger values indicate greater risk. $\Delta q$ is a measure of a species' potential of hyperstability, where catch rates will remain high as the population declines. Note that American lobster, longfin squid, sea raven, and sea scallop lacked resilience estimates and were not included. 